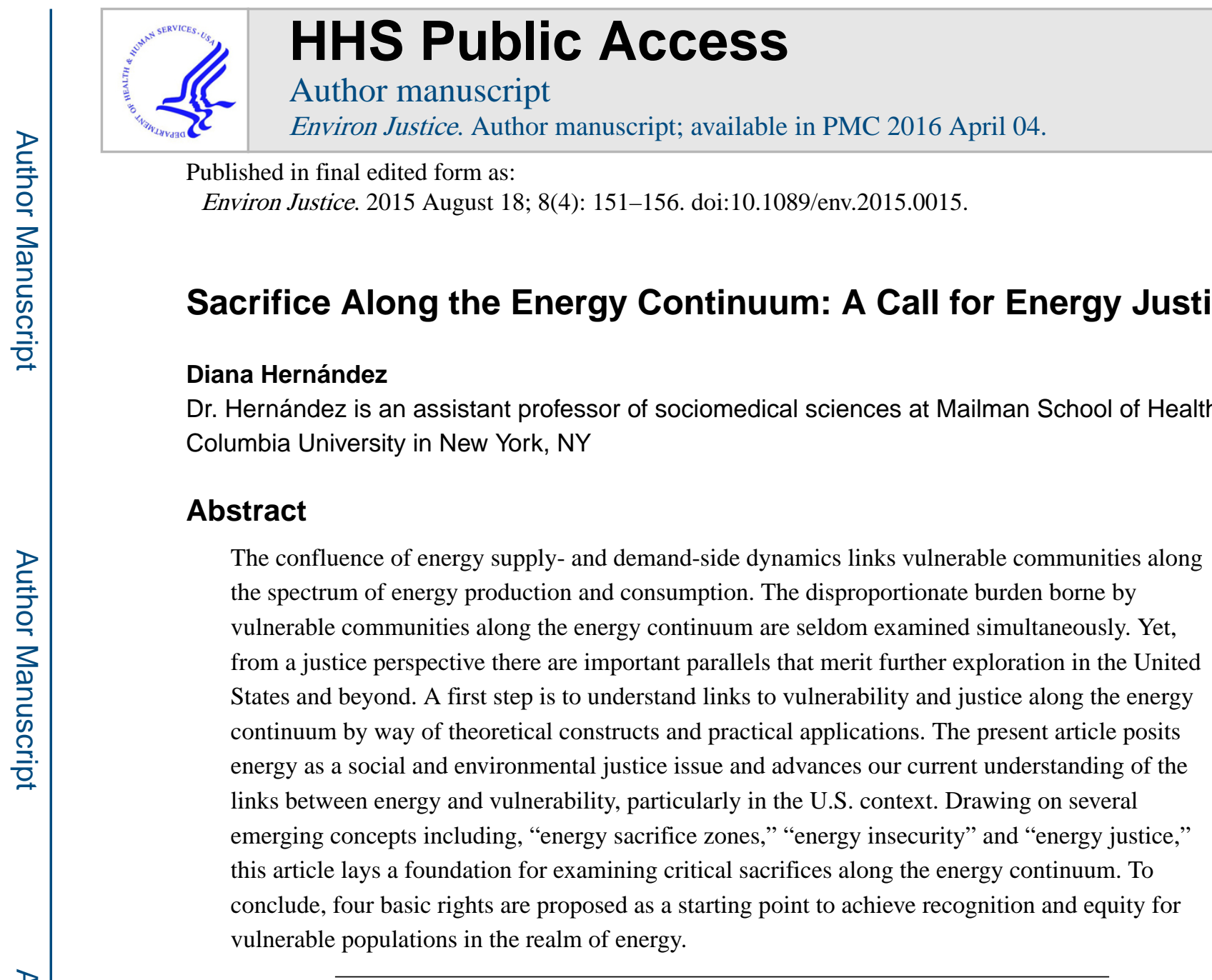

The connections between Dimock, Pennsylvania and Detroit, Michigan may not be entirely obvious at first glance. Dimock is a rural township with a population of 1,398 residents, the majority of which are white $(99 \%)$ and earn a median income of $\$ 43,343 .{ }^{1}$ Detroit, a key urban area in the U.S., has a population of 688,701 , most residents are African American (82\%) followed by whites (8\%) and Latinos $(7.5 \%)$ with a median household income of less than $\$ 23,600{ }^{2}$ While strikingly different on the surface, the links between Dimock and Detroit are embedded in an energy continuum that involves the production and consumption of energy in the context of vulnerability.

Dimock is known as "ground zero" in the hydraulic-fracturing debate. As featured in the acclaimed documentary Gasland, Dimock represents the martyrdom attached to modern energy production at the hand of hydraulic-fracturing. ${ }^{3}$ Fracking, as it is more commonly referred to, entails rushing chemical compounds, water, and sand underground to extract natural gas and oil for fuel production. ${ }^{4}$ Subsequently piped into homes and businesses throughout the U.S., natural gas powers heating and cooling systems, stoves, and vehicles among other uses. ${ }^{4}$ Places like Dimock are quintessentially rendered "energy sacrifice zones," as the contentious process of fracking presents hazards such as groundwater

Address correspondence to: Diana Hernández, Mailman School of Public Health, Columbia University, 722 West 168th St., Room 903, New York, NY 10032, dh2494@ columbia.edu.

Author Disclosure Statement: The author has no conflicts of interest or financial ties to disclose. 
contamination, air quality degradation, heightened susceptibility to earthquakes, and marked risks to human health. ${ }^{5-10}$ However, the evidence is deeply debated. ${ }^{11}$

On the other side of the energy spectrum, Detroit residents can barely afford to keep the lights on. In the Detroit Metropolitan Area, utilities are a prominent source of hardship in the aftermath of the Great Recession. Survey results of area residents indicate that almost 27 percent of low-income households fell behind on utility payments and an additional seven percent experienced a utility shut-off. ${ }^{12}$ Race and socioeconomic status played key roles in determining those impacted by utilities hardship. African American households were most affected. Blacks were almost twice as likely as non-blacks to report being behind on utilities payments ( $41 \%$ versus $22 \%$ ) and over three times more likely to experience a utility service shut-off than non-blacks (15\% versus $4 \%$ ). Low (38\%) and moderate-income (32\%) groups were disproportionately more likely to be behind on utilities payments as well as to experience a shut-off (14\% and 5\%, respectively) compared to higher income households in each category ( $14 \%$ and $2 \%$, respectively). ${ }^{12}$ As indicated by such widespread utilities hardship, households in Detroit are sacrificing to meet their household energy demands.

As both a social and environmental issue, the intersection of energy and poverty presents untapped and timely possibilities for seeking justice and equity for those sacrificed and sacrificing vis-à-vis energy. The confluence of energy supply- and demand-side dynamics links vulnerable communities across the energy production and consumption spectrum. The disproportionate burden borne by vulnerable communities along the energy continuum are seldom examined simultaneously. Yet, from a justice perspective there are important parallels that merit further exploration in the United States and beyond. Furthermore, the common omission of energy in current environmental and social justice debates equates to lost opportunities to act and demand more in the interest of affected populations. A first step is to understand links to vulnerability and justice along the energy continuum by way of theoretical constructs and practical applications.

The present article advances our current understanding of the links between energy and vulnerability, particularly in the U.S. context. It is structured as follows. First, the term "energy sacrifice zones" is used to describe unfavorable dynamics affecting vulnerable communities in the energy production process. ${ }^{13}$ Second, the conceptual construct of "energy insecurity" is presented to explain hardships experienced by low-income households with respect to the cost burdens of household energy, poor housing quality, and related coping strategies. ${ }^{14}$ Third, the emerging concept of "energy justice" is applied to issues of recognition and distributive and procedural justice pertaining to energy problems of the poor. ${ }^{15}$ To conclude, four basic rights are proposed in an effort to achieve recognition and equity for vulnerable populations in the realm of energy.

\section{Energy Sacrifice Zones}

The ability to meet rising domestic and global energy demands at a reasonable rate often comes with environmental and human costs. As energy production has become more aggressive, there are higher premiums for some individuals and communities so that the greater whole might experience unencumbered access to the basic good of energy. ${ }^{16}$ Certain 
areas of energy production in the U.S. have been sacrificed to satisfy the best interest of the nation's energy needs. ${ }^{13}$ "Energy sacrifice zones" have been characterized as an unfortunate byproduct of high demand for energy coupled with the lack of comprehensive energy policy designed to protect areas that generate the energy sources modern society takes for granted. ${ }^{13}$ Nevertheless, the sacrifice is uneven in multiple ways.

Energy production spanning nuclear, coal, oil, gas, biomass/incineration, and hydroelectric methods have disproportionately impacted low-income and communities of color. ${ }^{17} \mathrm{~A}$ policy brief produced by the Environmental Justice Network, describes a variety of infractions ensued by energy production across these mediums. ${ }^{18}$ Fracking, as described earlier, is an accelerated method of extracting natural gas well beneath the surface of rural landscapes most often in low-income communities that subsequently contend with air pollution and water contamination. This process has contributed to high morbidity and mortality rates from cancer, cardiovascular, neurological, respiratory, and developmental disorders; reduced productivity; and a poorer quality of life. ${ }^{19}$ Furthermore, while the use of coal has significantly declined, in part, because of the efforts of environmental activists, coal dependence continues to fuel mountaintop removal in the Appalachian region and generate air pollution from coal-fired power plants in African American and low-income communities. ${ }^{13}$

Several methods often considered clean or renewable sources of energy—nuclear, biomass, and hydroelectric — directly and indirectly impact vulnerable communities. ${ }^{18}$ Nuclear power pollutes air and water in the uranium mining process and produces solid waste often disposed of in low-income communities of color. ${ }^{17}$ Biomass incineration transforms materials such as trash, rubber, industrial, plant, and animal waste into useable energy in the form of electricity, biodiesel, and ethanol. ${ }^{19}$ The combustion process, however, is responsible for gaseous emissions of carbon monoxide, particulate matter, methane, volatile organic compounds, and nitrogen containing compounds. ${ }^{19}$ These environmental impacts are incongruous with biomass' distinction as a renewal energy source while concurrently jeopardizing the health of residents in impacted communities. Finally, hydroelectric power plants generate electricity while also increasing the risk of flooding and flood-based displacement while also escalating exposure to harmful toxins such as mercury, dioxins, and greenhouse gas emissions. ${ }^{20}$ The examples of the hazards of energy production and the disproportionate impact on vulnerable communities are made possible by an insatiable energy demand that continues to soar. The increased energy demand warrants greater and faster production even as certain individuals and communities are sacrificed to make this possible. $^{21}$

\section{Energy Insecurity And Everyday Sacrifices}

Economic vulnerability engenders sacrifice. "Energy insecurity" denotes the everyday challenges in meeting basic household energy needs. The concept is characterized by three elements—economic, structural, and behavioral—that coalesce as an underappreciated form of hardship among low-income Americans. ${ }^{14}$ Economic energy insecurity is measured as the disproportionate share of household income allocated to energy expenses with those that exceed a 10 percent threshold categorized as experiencing economic energy insecurity. ${ }^{22}$ 
Structural energy insecurity is marked by physical deficiencies in the home environment such as drafty windows, poor insulation, inefficient appliances, and faulty heating and cooling systems. Maintaining thermal comfort and controlling conditions of humidity and dampness are encumbered by the occurrence of structural energy insecurity. ${ }^{23}$ Finally, households impacted by the economic and/or structural facets of energy insecurity prompt behavioral responses to cope with these adverse conditions using approaches such as extreme energy conservation, seeking fuel assistance, and using improvisational heating alternatives such as space heaters and ovens to supply heat. ${ }^{23}$ While evidence on energy insecurity is emerging it remains limited. ${ }^{14}$

National statistics, however, from the American Community Survey and the American Housing Survey along with qualitative observations provide insights into the phenomenon of energy insecurity in the United States. Hernández, Aratani, and Yang (2014) examined economic energy insecurity (EI) based on the 2011 American Community Survey to demonstrate the extent to which families with children are burdened by disproportionate energy expenditures. ${ }^{23}$ Results published in a National Center for Children in Poverty policy brief indicate that more than half of families affected by economic EI live in poverty (under $100 \%$ of the federal poverty level) and about one-third are extremely poor. ${ }^{23}$ Also, approximately half of all households facing economic EI are African American, and about one-third are white. Lastly, over half of families experiencing economic EI are renters; 41 percent are homeowners. Similar results were found in the report referenced in the opening paragraph whereby the most prevalent hardship among Detroit households was related to paying utility expenses (27\%) followed by food insecurity (26\%), forgone medical care and phone service shut-off (22\% each), as well as falling behind on housing expenses (9\%). Many of these hardships were also experienced simultaneously. ${ }^{12}$ Unfortunately, energy insecurity has not been systematically measured in large-scale surveys, nevertheless the results summarized herein indicate that this phenomenon affects many households and therefore deserves more public and policy recognition.

The most recent results from the American Housing Survey demonstrate disparities in the structural elements related to energy insecurity evidenced by the disproportionate burden of physical housing problems experienced by racial ethnic minorities, the elderly, and the poor. ${ }^{24}$ African Americans and households below the poverty level, in particular, are more likely to report moderate and severe physical problems related to heating, plumbing, and maintenance. Specific to heating problems, elderly residents were most likely to report being uncomfortably cold for 24 hours or more and to experience a utility interruption. All groups were similarly at risk for heating equipment breakdowns but poor households most often indicated inadequate insulation and heating capacity as well as hardships related to the cost of heating. These findings suggest that aspects of structural energy insecurity are widespread and plague the most vulnerable households in the U.S. ${ }^{24}$

When facing economic and structural energy insecurity, Hernández (forthcoming) found that families employ positive and negative coping strategies. ${ }^{23}$ First, energy insecure households diligently conserved energy and enlisted resources such as fuel assistance and weatherization assistance. Second, families that encountered inadequate heating capacity improvised with alternatives such as ovens and space heaters thereby increasing toxic and 
hazardous exposures. In addition, energy insecure households moved more frequently and were more prone to stress.

Ironically, poor households across the energy continuum suffer everyday hardships in the production and consumption of energy. Their plights can be reconciled with greater emphasis on justice and equity borrowing from the successes of social and environmental justice movements, though specifically geared toward advancing energy justice.

\section{Energy Justice}

Social justice initiatives have emphasized racial and socioeconomic disparities in a variety of health, education, and economic opportunities and burdens. In the past few decades, social justice advocates have made important strides regarding food and housing affordability, access to clean water, health care, and combating discriminatory policies related to sexual orientation and mass incarceration. ${ }^{25}$ Similarly, environmental justice efforts have centered on reducing exposures to a variety of sources of air pollution and unwanted land uses. ${ }^{26}$ Toxic waste sites and other environmental hazards have motivated a movement to identify and combat environmental racism. ${ }^{26}$ Likewise, actions against fracking, mountaintop removal, and the siting of undesirable industrial facilities in poor rural areas have been prioritized as environmental justice issues. While the social and environmental justice movements in the U.S. are marked by important achievements, key racial and socioeconomic disparities persist. ${ }^{27}$ Furthermore, the range of issues remains relatively narrow. For instance, energy remains outside of the purview of these movements. Despite the overlap in these ongoing battles, the specific role of energy has not been directly taken up as a social or environmental justice issue.

Energy justice calls for attention to equitable distribution of energy benefits and burdens and raises consciousness regarding vulnerable groups vis-à-vis energy including access and affordability. While no firm definition of energy justice exists, several authors offer useful conceptualizations that build on the basic tenets of the social and environmental justice movements, though ranging in their emphasis regarding the role of consumers and markets. Borrowing from scholars and activists beyond the United States, a review of the operationalization of energy justice is offered below, followed by concrete ideas for applying the principles of energy justice along the energy continuum with particular regard for the interests of vulnerable populations.

Guruswamy (2010) asserts: "Energy justice conjugates justice with energy. Justice is the first virtue of social institutions; energy is a fundamental need and the driving determinant of human progress. Energy Justice seeks to apply basic principles of justice as fairness to the injustice evident among the energy oppressed poor. ..."28 Guruswamy links energy justice to sustainable development particularly in the context of developing nations where many "energy oppressed poor" (EOP) do not have access to life sustaining energy. Sustainable energy, the author asserts, "will enable the energy oppressed poor to develop, and break the bonds of poverty and energy deprivation." ${ }^{28} \mathrm{He}$ argues, that EOP's right to sustainable development "must be re-affirmed." 
Whereas infrastructure presents the most significant barrier to energy in the poorer nations, the circumstances surrounding energy justice in industrialized nations are more nuanced. As cited by Hall, Saunders proposed the following working definition of energy justice in the UK domestic sector context:

[Energy justice] is about ensuring that everyone can afford the energy they need for health and well-being. It comprises a range of factors which are to do with the distributional effects of how competitive (or NOT so competitive) energy markets are working and it is also to do with how government policies affect the way in which energy is regulated, produced and priced, as well, of course as the way in which individual household reliance on energy and needs comes into play, and ensuring the needs of vulnerable households are met. ${ }^{29}$

Saunders' working definition of the term focuses on energy as a basic need, with attention to its affordability, considerations of market forces in the distribution of energy, and deliberations on the role of energy policy. This definition, however fails to account for undue burdens and inequalities associated with the production of energy, not merely its consumption, distribution, and regulation. The production, as illustrated above, carries implications for health and economic solvency at individual and community levels. A full view of energy justice must thus take into account the complete spectrum of issues from production and distribution to ethical consumption and government regulation.

The most comprehensive view of energy justice available in the literature is espoused by Sovacool, Sidortsov, and Jones. ${ }^{15}$ The authors offer a principle-based conceptualization of energy justice that factors in four assumptions regarding human rights and dignities, capabilities, and the role of energy in ensuring fruitful and productive lives. These assumptions view energy instrumentally and as a prerequisite to realizing the essentials of life afforded by energy. Premised on these basic assumptions, the authors propose a principle-based framework of energy justice consisting of two main components:

Prohibitive principle, which states that "energy systems must be designed and constructed in such a way that they do not unduly interfere with the ability of people to acquire those basic goods to which they are justly entitled," and

Affirmative principle, which states that "if any of the basic goods to which people are justly entitled can only be secured by means of energy services, then in that case there is also a derivative entitlement to the energy services."

The prohibitive and affirmative principles of energy justice are based on the view that energy serves as a material necessity for many of the basic goods to which people are entitled such as food, a livelihood, and the opportunity to progress and prosper (i.e., studying, employment, and healthy cook stoves, etc.). These principles also make obvious that the externalities associated with energy systems-production and infrastructure—can potentially enhance or impede the fulfillment of "fundamental goods such as security and welfare." As with Guruswamy, the undertone of the energy justice issue posited by Sovacool et al., is globally focused. The authors even assert that, "energy justice has been egregiously ignored in international discourse about energy and the environment." However, returning to 
the Dimock-Detroit examples above, it is also abysmally overlooked in the U.S. domestic context. A call for energy justice in the U.S. is not only timely; it is long overdue.

\section{A Call for Energy Justice}

In 1991, delegates to the First National People of Color Environmental Leadership Summit established the Principles of Environmental Justice (EJ) with 17 points that have formed the basis for the global environmental justice movement. The EJ principles delineate the imperative to recognize diversity along spiritual, cultural, linguistic, epistemological beliefs, and the rectification of the environmental infractions that have impinged the political, economic, and cultural lives of disenfranchised groups over time. In keeping with these demands and in accordance with Sovacool et al.'s conceptualization of energy justice, the following four rights form the basis of demands along the energy continuum:

1. Right to healthy, sustainable energy production. Energy production spanning nuclear, coal, oil, gas, biomass/incineration, and hydroelectric methods should be held to the highest standards of protection of the environment and human health. Rigorous, timely, and objective environmental health assessments should be conducted at various stages of planning and operating these energy production efforts. Impacted community members should be engaged in the data collection process and provided with effective, low-cost tools to monitor air quality, harmful exposures and track experiences pertaining to the environment and health. As negative consequences are discovered, rapid and appropriate measures must be taken to remediate the root cause and/or halt operations completely. Communities and enforcement agencies should work together to ensure proper monitoring and necessary action including laws and policies enacted to protect against further harm. For example, the recent decision to ban hydraulic-fracturing in New York State followed evidence of water, soil, and air contamination, negative impacts to human health, and diminishing economic returns. ${ }^{30}$

2. Right to best available energy infrastructure. Recognizing that the development of energy infrastructure occurs within the context of local and regional planning and that existing infrastructure warrants periodic upgrades, the right to the best available energy infrastructure would privilege areas lacking in service and in need of modernization. The right to the best available energy infrastructure would ensure that energy resources and burdens are more equitably distributed.

3. Right to affordable energy. Economic energy insecurity represents an inability to afford a basic tenet of everyday life-energy. The burdens associated with economic energy insecurity are largely borne by low-income groups and other vulnerable populations including the elderly and infirmed. The United Nations' Universal Declaration of Human Rights (1948) specifies 30 inalienable global rights due to all members of society. ${ }^{31}$ While affordable energy is not explicitly referenced, the right to energy is largely subsumed under Article 25 which notes that:

Everyone has the right to a standard of living adequate for the health and well-being of himself and of his family, including food, clothing, housing 
and medical care and necessary social services, and the right to security in the event of unemployment, sickness, disability, widowhood, old age or other lack of livelihood in circumstances beyond his control.

Affordable energy thereby constitutes a basic entitlement that should be accessible to all regardless of socioeconomic status. Realizing this right may require government and utilities-based subsidies that assist households facing economic hardships. It may also necessitate investments in more efficient building infrastructure in low-income housing.

4. Right to uninterrupted energy service. In extension of the right to affordable energy, the right to unencumbered energy services would ensure that provisions are in place to prevent utility service interruptions due to non-payment and arrearages. At present, most states offer shut-off protections based on season, outdoor temperatures, or medical conditions and many grant immunity from disconnection as per compliance with payment plans. ${ }^{32}$ The policies, however, vary by state and do not prohibit utility debt accumulation or bestow indefinite protection. Therefore, households experiencing chronic energy insecurity can be subjected to shut-offs; accrue financial liabilities; and jeopardize health, residential stability, and economic well-being. By recognizing energy as a basic need and human right, households would be protected by moratoriums whereby energy services would remain available indefinitely particularly for vulnerable households.

The realization of these four basic rights to energy justice requires action at multiple levels. At the individual level, the "ethical consumption" of energy would reduce the demand for intense energy production and, in turn, the burden borne in energy sacrifice zones. Energy conservation methods would also reduce energy expenditures, therefore diminishing the prevalence of energy insecurity. At the macro level, the creation and enforcement of regulations that mandate ambitious energy efficiency and higher energy performance standards, the development and scalability of renewable sources of energy, as well as differentiated rates and subsidies for the neediest households would raise accountability on the part of manufacturers, utility companies, and the purveyors of low-income housing. These measures are crucial if energy is to be acknowledged as a basic human right with special attention to minimizing sacrifice of vulnerable groups along the energy continuum.

\section{References}

1. Dimock township, Susquehanna County, Pennsylvania (PA). http://www.city-data.com/township/ Dimock-Susquehanna-PA.html

2. Detroit, Michigan. http://www.city-data.com/city/Detroit-Michigan.html

3. Rubinkam, Michael. Dimock, PA Water Testing Results Expected To Impact Fracking Debate. Huffington Post. Mar 5. 2012 http://www.huffingtonpost.com/2012/03/05/dimock-pa-water-testingresults_n_1320978.html

4. Mokhatab, S.; Poe, WA. Handbook of Natural Gas Transmission and Processing. Gulf Professional Publishing; 2012.

5. Degenhardt R. Hydraulic Fracturing and Groundwater Contamination: Can Disclosure Rules Clarify What's in Our Groundwater. Ecology L Currents. 2012; 39:39.

6. Merrill TW. Four Questions About Fracking. Case W Res L Rev. 2012; 63:971. 
7. Kovats S, Depledge M, Haines A, Fleming LE, Wilkinson P, Shonkoff SB, et al. The Health Implications of Fracking. Lancet. 2014; 383(9919):757-758. [PubMed: 24581655]

8. Cartwright E. Eco-risk and the Case of Fracking. Cultures of Energy: Power, Practices, Technologies. 2013:201-212.

9. McDermott-Levy R, Kaktins N, Sattler B. Fracking, the Environment, and Health. AJN The American Journal of Nursing. 2013; 113(6):45-51. [PubMed: 23702766]

10. Swartz T. Hydraulic Fracturing: Risks and Risk Management. Nat Resources and Env't. 2011; 26:30.

11. Mitka M. Rigorous Evidence Slim for Determining Health Risks from Natural Gas Fracking. JAMA. 2012; 307(20):2135-2136. [PubMed: 22618904]

12. National Poverty Center Policy Brief. Material Hardships during the Great Recession: Findings From the Michigan Recession and Recovery Study. Brief \#. 2012; 35

13. Buckley, GL.; Allen, L.; Purdy, J. Mountains of Injustice: Social and Environmental Justice in Appalachia. Morrone, M.; Buckley, GL., editors. Ohio University Press; 2011.

14. Hernández D. Energy Insecurity: A Framework for Understanding Energy, the Built Environment, and Health among Vulnerable Populations in the Context of Climate Change. American Journal of Public Health. 2013; 103(4):e32-e34. [PubMed: 23409876]

15. Sovacool, BK.; Sidortsov, RV.; Jones, BR. Energy Security, Inequality and Justice. Routledge; 2013.

16. Walker G. The Dynamics of Energy Demand: Change, Rhythm and Synchronicity. Energy Research and Social Science. 2014; 1:49-55.

17. Taylor, DE. Toxic Communities: Environmental Racism, Industrial Pollution, and Residential Mobility. NYU Press; 2014.

18. Environmental Justice Network. Energy and Environmental Justice. http://www.energyjustice.net/ files/ej/energy-ej.pdf

19. Tillman DA. Biomass Cofiring: The Technology, the Experience, the Combustion Consequences. Biomass and Bioenergy. 2000; 19(6):365-384.

20. dos Santos MA, Rosa LP, Sikar B, Sikar E, dos Santos EO. Gross Greenhouse Gas Fluxes From Hydro-Power Reservoir Compared to Thermo-Power Plants. Energy Policy. 2006; 34(4):481-488.

21. Weinhold B. The Future of Fracking. Environmental Health Perspectives. 2012; 120(7):A272A279. [PubMed: 22759752]

22. Hernández, D.; Aratani, Y.; Jiang, Y. Energy Insecurity among Families with Children. New York: National Center for Children in Poverty, Columbia University Mailman School of Public Health; 2014.

23. Hernández D. Power for the Poor: Understanding the Key Dimensions of Energy Insecurity. Forthcoming.

24. U.S. Census Bureau. American Housing Survey. 2013. http://www.census.gov/programssurveys/ahs/data/2013/national-summary-report-and-tables—ahs-2013.html

25. Tyler, TR.; Boeckmann, RJ.; Smith, HJ.; Huo, YJ. Social Justice in a Diverse Society. West-view Press; 1997.

26. Schlosberg, D. Defining Environmental Justice: Theories, Movements, and Nature. Oxford University Press; 2007.

27. Bullard, RD.; Lewis, J. Environmental Justice and Communities of Color. Sierra Club Books; 1996.

28. Guruswamy L. Energy Justice and Sustainable Development. Colo J Int'1 Envtl L \& Pol'y. 2010; 21:231.

29. Hall SM. Energy Justice and Ethical Consumption: Comparison, Synthesis and Lesson Drawing. Local Environment. 2013; 18(4):422-437.

30. New York State Department of Health. A Public Health Review of High Volume Hydraulic Fracturing for Shale Gas Development. https://www.health.ny.gov/press/reports/docs/ high_volume_hydraulic_fracturing.pdf

31. United Nations'. Universal Declaration of Human Rights. 1948. http://www.un.org/en/documents/ udhr/ 
32. LIHEAP Clearinghouse. State Disconnection Policies. http://www.liheapch.acf.hhs.gov/ Disconnect/disconnect.htm 